\title{
¿HA SIDO LA DINÁMICA DE LA BALANZA DE PAGOS REALMENTE UNA RESTRICCIÓN PARA EL CRECIMIENTO ECONÓMICO EN MÉXICO? PARTE I*
}

\author{
Isela Elizabeth Téllez-León** \\ Escuela Superior de Economía, Instituto Politécnico Nacional \\ Francisco Venegas-Martínez \\ Escuela Superior de Economía, Instituto Politécnico Nacional \\ (Recibido 15 de abril 2013, aceptado 26 de junio 2013)
}

\begin{abstract}
Resumen
Esta investigación analiza si la dinámica de la Balanza de Pagos (BP) de México ha sido una restricción para el crecimiento económico de México. La literatura sobre el tema analiza la restricción al crecimiento de la Balanza de Pagos basada en el problema del desequilibrio externo. La evidencia empírica ha mostrado que la mayoría de los países de América Latina han tenido la restricción de brecha externa. Aunque los modelos de crecimiento restringido que estudian este tema han sido identificados en tres enfoques para su análisis (el enfoque de demanda del modelo de Thirlwall, el modelo estructuralista o de tres brechas (externa, de ahorro y fiscal) y el enfoque institucionalista), en esta investigación se propone un análisis dinámico a través de la estimación de modelos VAR y VEC. El objetivo es contribuir con evidencia empírica a la creciente controversia sobre el impacto del sector externo en el crecimiento económico. Diversos estudios sobre este tema se han realizado con base en diferentes enfoques para: Argentina (Fugarolas y Matesanz, 2005), Ecuador (Velastegui, 2007), Bolivia (Averilca y Risso, 2007), Brasil (Gonzaga, 2003 y Brito, 2008), Colombia (Velasco, 2006 y García y Quevedo, 2005), entre otros. El análisis econométrico de los modelos propuestos se presenta en el siguiente número de la revista, parte II de la presente investigación, en la cual se analizarán relaciones de largo y corto plazo. Los resultados sugieren que la estabilidad macroeconómica de los últimos años ha creado un ambiente atractivo para el desarrollo del sector externo; sin embargo, las medidas monetarias no son la única opción para corregir los desequilibrios de la BP.
\end{abstract}

* El presente artículo corresponde a la primera parte de una investigación sobre la dinámica de la balanza de pagos y el crecimiento económico de México. El siguiente número de la revista presentará la segunda parte del trabajo, la cual contempla el análisis econométrico de los modelos propuestos.

** Escuela Superior de Economía (ESE), Plan de Agua Prieta 66, Unidad Profesional Lázaro Cárdenas, Col. Plutarco Elías Calles, Delegación Miguel Hidalgo, C.P. 11350, México, Distrito Federal. Correo electrónico:tellezelizabeth_2015@yahoo.com 


\begin{abstract}
This paper analyzes whether the dynamics of the balance of payments (BP) of Mexico has been a constraint on Mexicos Economic Growth. The literature on the subject discusses the growth restriction of the balance of payments based on the external imbalance problem. Empirical evidence has shown that most Latin American countries have had the external gap constraint. Though restricted growth models studying this issue have been identified in three approaches for analysis (the demand approach of Thirlwalls model, the structural model or three gaps (external, savings and fiscal) and the institutional approach), this research proposes a dynamic analysis through the estimation of VAR and VEC models. The goal is to contribute to the growing empirical evidence of the impact of the external sector on economic growth. Several studies on the theme have been made based on different approaches for the case of: Argentina (Fugarolas and Matesanz, 2005), Ecuador (Velastegui, 2007), Bolivia (Averilca and Risso, 2007), Brazil (Gonzaga, 2003 and Brito, 2008), Colombia (Velasco, 2006 and Garcia and Quevedo, 2005), among others. Econometric analysis of the proposed models is presented in the next issue of the Journal, part II of this research, which will analyze long and short term relations. The results suggest that the macroeconomic stability in recent years has created an attractive environment for the development of the external sector; however, monetary measures are not the only option to correct the imbalances of the BP.
\end{abstract}

Clasificación F32, F42, C13.

Palabras clave: Balanza de pagos, Crecimiento económico, VAR y Cointegración.

\title{
1. Introducción
}

La restricción al crecimiento proveniente de la dinámica de la Balanza de Pagos ha sido revisada desde hace mucho tiempo por investigadores de la CEPAL, entre los que destacan los trabajos pioneros de Noyola, Urquídi y Furtado (1957) y Prebisch (1959), quienes también enfatizan la existencia de desequilibrios estructurales de las economías en desarrollo. Los principales señalamientos de esta línea de investigación apuntan a que la tasa de crecimiento de una economía en desarrollo es limitada principalmente por la capacidad de ahorro, de este punto se deriva la posibilidad de generar ahorro por la relación comercial y es cuando surge la necesidad de estudiar la dinámica de su balanza de pagos para saber si se comporta o no una restricción al crecimiento económico y para examinar la posibilidad de ofertar divisas.

Los estudios de crecimiento económico restringido por el sector externo, si bien centran su atención en tres enfoques para analizar la dinámica de la Balanza de Pagos y el crecimiento económico, en esta investigación se pretende analizar el referido tema a través de un análisis dinámico, razón por la cual se estiman modelos VAR y VEC, los cuales permiten estudiar las relaciones de largo y corto plazo a diferencia de los modelos dinámicos con enfoques preestablecidos; otras investigaciones que utilizan modelos de series de tiempo han sido aplicadas a: Brasil (Gonzaga, 2003), Colombia (Velasco, 2006 y García y Quevedo, 2005) y México (Lizardi, 2007). No obstante, una característica distintiva de este documento es el análisis dinámico para examinar relaciones de largo y corto plazo.

Entre las teorías de crecimiento restringido por el sector externo se encuentran las que tienen restricciones sectoriales de oferta como en Prebisch, 1959 y Taylor, 1994. Otras teorías que enfatizan el lado de la demanda desde la inversión y el ahorro forzoso son las de Schumpeter, 1934 y Thrirlwall, 
1979, en las que la variable determinante en el largo plazo es la brecha externa. Recientemente se ha incorporado el enfoque institucional que considera a las instituciones como la casusa entre las diferencias en crecimiento y generación de desequilibrios sectoriales. Estos tres enfoques han obtenido evidencia empírica a su favor en varios países latinoamericanos: Ecuador (Velastegui, 2007), Argentina (Fugarolas, 2005), Bolivia (Averilca y Risso, 2007), Brasil (Gonzaga, 2003 y Brito, 2008), Colombia (Velasco, 2006 y García y Quevedo, 2005), Mexico (Moreno-Brid, 1999 y 2003, Loría y Fujii 1997, Loría, 2001 y Ocegueda 2003). En tanto que, para un análisis comparativo de países se encuentran las investigaciones sobre: Argentina, Brasil, Colombia y México (en Lopez y Cruz, 2000), y para el caso de Costa Rica, El Salvador, Guatemala, Honduras y Nicaragua (Moreno-Brid y Pérez, 1999), entre otros.

El objetivo de esta investigación consiste en explorar empíricamente la referida hipótesis durante el periodo de 1980-2010 para el caso mexicano en un enfoque que captura relaciones de corto y largo plazo y que examina los efectos de cada componente de la balanza de pagos en el crecimiento del PIB. En el caso de México, el déficit de la cuenta corriente, en diferentes periodos, ha sido financiado con flujos de inversión extranjera directa; aunque este hecho ha sido criticado por algunos economistas argumentando una fuerte dependencia con el exterior. Sin embargo, se ha observado que con la aplicación de políticas estructurales adecuadas se puede, en el largo plazo, disminuir dicha dependencia. Mientras tanto, en el corto plazo, es prudente considerar políticas monetarias que estabilicen las condiciones macroeconómicas, ya que si se visualiza un escenario sin acciones monetarias podría repetirse la reducción excesiva de reservas internacionales. ${ }^{1}$

Con la finalidad de considerar el cambio de régimen del tipo de cambio la Balanza de Pagos (BP) de México, el análisis histórico se fracciona en dos periodos 1980-1994 y 1995-2010, los cuales corresponden al cambio de régimen del tipo de cambio. En el segundo caso, la adopción del tipo de cambio flexible deja la puerta abierta para la aplicación de la política monetaria y sus instrumentos. El tema tiene relevancia actual por la preocupación que genera el sector externo y la estabilidad macroeconómica como se expresa a través de los documentos de investigación del Fondo Monetario Internacional (FMI), los cuales muestran un gran interés sobre la estabilidad de la BP para países en desarrollo. En este sentido el FMI ha cambiado los criterios de clasificación y el registro de la quinta edición del Manual de BP, dichos cambios se analizarán en el presente documento.

En virtud de que el FMI ha reestructurado la medición de la BP, surge una motivación adicional por analizar la BP, pues de 1980 al primer trimestre de 2010 en México se tenía una presentación acorde con la cuarta edición del Manual de BP del FMI publicada por el Banco de México. A partir del segundo trimestre de 2010 se efectuaron varios cambios para mostrar la presentación acorde con la quinta edición del Manual de la BP del FMI, en la cual se incluye la balanza de bienes adquiridos en puertos por medios de transporte y se redefine a la balanza comercial como balanza de mercancías generales, además se separan

\footnotetext{
1 Si la BP no está en equilibrio, lo cual es un fenómeno de corto plazo, entonces ésta usualmente se ajusta a través del tiempo con las medidas apropiadas (Du Plessi et al. 1998).
} 
por balanzas los servicios y la renta. En este contexto se examina, en el presente trabajo, el comportamiento de la BP para el caso de México y su relación con el crecimiento económico.

El análisis teórico que fundamenta el modelo empírico es el Enfoque Monetarista (EM). En general, se observa que la literatura sobre el tema inició con el análisis de la BP a través de la Ley de Walras, en la cual un exceso de demanda de dinero puede ser controlado por las transacciones, es decir, por la venta de bienes y servicios o por valores en mercados extranjeros. En forma similar, el exceso de oferta de dinero se puede restringir con la compra de bienes y servicios del exterior o por la inversión en el extranjero teniendo como resultado la salida de reservas.

No obstante, el enfoque que predominó sobre la BP con tipo de cambio fijo fue el EMBP. El desequilibrio de la BP se ajusta automáticamente si las autoridades monetarias no generan dinero a través de una política de esterilización (creación de nuevo crédito interno, Md. Abdus Salam, (1995)). ${ }^{2}$ En México, un claro ejemplo de la implementación de política de esterilización se puede observar durante 1980-1995. Posteriormente, se amplió el EMBP para incluir modelos de BP bajo tipo de cambio flexible, el cual generó otras implicaciones, las cuales se analizaran más tarde en el presente trabajo.

Este documento se organiza de la siguiente manera: en la siguiente sección se realiza una breve revisión de la literatura sobre la dinámica de la BP a través del estudio de los dos enfoques de BP, tipo de cambio fijo y flexible, esto permitirá analizar posteriormente la hipótesis de la posible restricción al crecimiento económico por la dinámica de la BP; en la sección 3 se describe y analiza el comportamiento de la BP durante 1980-2010 y su relación con el crecimiento económico; por último se presentan las primeras conclusiones derivadas del análisis estadístico, ya que en la segunda parte de esta investigación se desarrollarán los modelos dinámicos propuestos, con los que se obtendrán varios hallazgos empíricos y se derivaran recomendaciones en materia de política económica.

\section{Revisión de la literatura sobre la dinámica de la Balanza de Pagos}

En esta sección se revisa, brevemente, la literatura sobre el estudio de la BP, primero bajo el supuesto de tipo de cambio fijo y después bajo tipo de cambio flexible. Básicamente, el enfoque monetario de la BP puede verse como una relación dual con el enfoque monetario del tipo de cambio, ya que este enfoque resalta el papel del dinero y de otros activos en la determinación de la BP (EMBP), así como la determinación del tipo de cambio cuando éste es flexible (Frenkel, 1971) y (1981). Sin embargo, el fenómeno de la sustitución de las monedas en una cartera de activos cuestiona esta dualidad; véase al respecto, los trabajos de McKinnon (1981) y Spinelli (1983).

El modelo monetario de la BP originalmente se empleó en un marco para analizar ajustes de la BP bajo un tipo de cambio fijo (siendo el tipo de cambio un

\footnotetext{
2 Las políticas de esterilización consisten en operaciones de signo contrario (a través, por ejemplo, del mercado abierto) a las operaciones de cambio (que consisten en compra-venta de dólares, o de cualquier otra divisa internacional) realizadas por el Banco Central cuando la economía opera bajo un régimen de tipo de cambio fijo.
} 
ancla nominal). Después de la caída del sistema de Bretton Woods, el modelo fue modificado para implementar una teoría de la determinación del tipo de cambio, el cual ha tenido diversas transformaciones hasta llegar a las recientes aproximaciones monetarias que suponen precios perfectamente flexibles y se concentran en condiciones de equilibrio del mercado de dinero.

Es importante tener en cuenta que el enfoque monetario de la BP con tipo de cambio flexible no afirma que una inadecuada dirección monetaria es la única causa de algún desequilibrio. En este sentido, la modificación de la política monetaria no es la única solución posible para los problemas de la BP. En este sentido, el tipo de cambio como variable monetaria adquiere un papel relevante en la determinación del comportamiento de la BP, se trata de la solución de tipo de cambio flexible de acuerdo con el argumento de Mundell (1971), en el cual la flexibilidad del tipo de cambio garantiza el equilibrio exterior en todo momento. ${ }^{3}$

\subsection{Balanza de Pagos y oferta monetaria}

La asociación entre la BP de una economía y su oferta monetaria se puede expresar mediante el EMBP, ya que si hay un superávit o déficit en la cuenta corriente, entonces el mercado de dinero no funciona correctamente. Si la oferta de dinero es mayor que la demanda de dinero, entonces se crea un déficits; en caso contrario se tiene un superávit (Howard y Mamingi, 2002).

El enfoque monetario de la BP fue desarrollado en las décadas de los cincuentas y sesentas por investigadores del Fondo Monetario Internacional FMI: Jacques J. Polack, Harry G. Johnson y Robert A. Mundell. Otros investigadores que han trabajado con el EMBP son: Frenkel (1971), Johnson (1972), (1977a) y (1977b), Dornbusch (1971), Laffer (1969), Aghevli y Khan (1977), entre otros. La idea detrás del enfoque monetario es la estrecha relación que existe entre la BP y su oferta monetaria, en cuyo caso las variaciones de las reservas del Banco Central son el resultado de los cambios en el mercado de dinero.

Si además se considera el nivel de precios, entonces, el EMBP representa el valor actual de los activos, el dinero y la deuda extranjera. El enfoque monetario es explicado con un modelo sencillo que relaciona la balanza de transacciones oficiales con la evolución del mercado de dinero. En efecto, si se considera la definición del equilibrio en el mercado de dinero, en términos reales, se tiene que:

$$
M^{S} / P=L(i, Y)
$$

donde: $M^{S} / P$ es la oferta de dinero, en términos reales, que en equilibrio es igual a la demanda de dinero real, $L$ es una relación funcional, $i$ es la tasa de interés y $Y$ es el nivel de ingreso.

Sea $F^{*}$ el valor en moneda nacional de los activos extranjeros del banco central y $A$ el valor de sus activos nacionales que equivale al credito interno, ${ }^{4}$

\footnotetext{
3 Véase al respecto, los trabajos de Wilford and Wilford (1978) y Polak (1957).

4 El crédito interno (CI) está formado por los títulos de propiedad que tiene las autoridades monetarias sobre el sector público (deuda pública) y sobre el sector privado (préstamos concedidos a los bancos).
} 
$C I$, y $\mu$ es el multiplicador monetario que relaciona el total de los activos del banco central, $F^{*}+A$, con la oferta monetaria, entonces:

$$
M^{*}=\mu\left(F^{*}+A\right)
$$

Asi, el cambio en las reservas exteriores, $\Delta F^{*}$, en un determinado periodo de tiempo $\Delta t$, en el caso de un pais cuya moneda no sea divisa reserva, es igual al saldo de la balanza de transacciones oficiales. Al combinar las ecuaciones (1) y (2) se obtienen las reservas exteriores del banco central como sigue:

$$
F^{*}=(1 / \mu) P L(i, Y)
$$

Si se supone que $\mu$ se mantiene constante, el superavit de la balanza de transacciones oficiales esta dado por:

$$
\Delta F^{*}=(1 / \mu) \Delta[P L(i, Y)]-\Delta A .
$$

La ecuación anterior resume el enfoque monetario de la BP. El primer miembro de la ecuación de la derecha corresponde a las variaciones de la demanda nominal de dinero, si todo lo demás permanece constante, una disminución de la demanda de dinero produce un déficit de la balanza de transacciones oficiales, lo cual a su vez, conlleva a una disminución de la oferta monetaria manteniendo el equilibrio el mercado de dinero.

El otro término del lado derecho de la ecuación muestra los factores de la oferta en el mercado de dinero, por ejemplo, si todo lo demás permanece constante, una disminución del CI reduce la oferta monetaria en relación a la demanda de dinero, por lo que la BP registrará un superávit para aumentar la oferta monetaria y restablecer el equilibrio en el mercado monetario, ya que la balanza de transacciones oficiales es igual a la suma de la cuenta corriente y la cuenta de capital (excluyendo las reservas); antes del enfoque monetario se explicaba cada cuenta por separado. En este sentido, una aportación importante del enfoque monetario de la $\mathrm{BP}$ es destacar que muchos de los problemas de la $\mathrm{BP}$ son resultado de los desequilibrios del mercado monetario, por lo tanto una solución basada en política monetaria podría ser más adecuada.

El enfoque monetario se aplica usualmente a problemas de política económica producidos directamente por las variaciones de la demanda de dinero o de la oferta monetaria nacionales. ${ }^{5}$ El enfoque monetario de la BP es un enfoque muy útil, pero es recomendable revisarlo cuidadosamente antes de buscar soluciones a los problemas de política económica producidos directamente por las variaciones de la demanda u oferta de dinero doméstico. En la siguiente sección se incorpora el efecto Fisher y la tasa de interés en el enfoque monetario de precios flexibles.

5 Si la demanda de productos y, por lo tanto, la demanda de dinero disminuye al bajar la demanda de exportaciones, el enfoque monetario predice que un déficit de BP será resultado de una reducción de la demanda de exportaciones, y sería erróneo que los tomadores de decisiones llegaran a la conclusión de aplicar una contracción del CI para mejorar la BP, pues el desempleo incluso podría aumentar, ya que la causa del desequilibrio no fue meramente monetario. 


\subsection{Tasa de interés, precios flexibles y efecto Fisher}

En el enfoque monetario del tipo de cambio flexible se supone que los precios de los bienes son perfectamente flexibles, lo cual implica que la moneda de un país se deprecia cuando su tasa de interés nominal aumenta debido a la mayor inflación esperada futura.

Cuando los precios de los bienes son perfectamente flexibles, se tiene que el equilibrio del mercado de dinero tiene dos efectos ante un incremento de la tasa de crecimiento de la oferta monetaria de un país, lo que a su vez se traduce en un aumento en la inflación. De esta manera se tienen un incremento en la tasa de interés de acuerdo con el efecto Fisher y se produce un salto en el nivel de precios. El equilibrio del mercado de dinero se mueve por tanto de un punto de equilibrio a otro y como la oferta de dinero nominal no cambia rápidamente, la oferta de dinero real cae.

Por otro lado, la relación de paridad de poder de compra específica que el brinco del nivel de precios requiere una depreciación del tipo de cambio. De esta manera, en el mercado de divisas se deprecia el peso. El peso se deprecia a pesar del aumento en la tasa de interés, porque las mayores expectativas de una depreciación futura del peso frente al dólar provocan un desplazamiento hacia fuera de la rentabilidad esperada en pesos por los depósitos denominados en dólares. Este modelo, ilustra perfectamente el movimiento simultáneo de los mercados, con base en esta cualidad se especifican los modelos dinámicos propuestos. $^{6}$

\section{Dinámica de la Balanza de Pagos durante 1980-2010}

En la presente sección se realiza una descripción estadística del comportamiento de la BP y su relación con el crecimiento económico, con la finalidad de obtener implicaciones empíricas sobre la BP. Las cifras presentadas son oportunas y pueden ser actualizadas por Banxico debido al proceso constante de revisión en los componentes de la Balanza de Pagos.

En la gráfica 1 se observa que en el periodo 1983-1985 y en 1987 se presentaron superávits en la Cuenta Corriente (CC). Es importante notar que el mayor superávit fue de 5 mil 859.6 millones de dólares y ocurrió en 1983 debido al favorable comportamiento de la Balanza Comercial (superávit de 14 mil 104.9 millones de dólares) y al saldo neto de las transferencias por 1 mil 172.7 millones de dólares. En tanto que la Cuenta Financiera (CF) presentó un máximo en 2010 (36 mil 16.8 millones de dólares) debido al comportamiento máximo de los pasivos y una cifra mínima histórica en los activos.

En 2010 se presentó un máximo en la variación de la Reserva Internacional Neta (22 mil 758.7 millones de dólares) y los Errores y Omisiones en 2010 tuvieron un monto negativo de 7 mil 647.2 millones de dólares. Dicho comportamiento obedece a una de situación de mayor certidumbre y a la mayor movilidad de capitales.

6 Véase también Obstfeld y Rogoff (1995) y (1999). 
Gráfica 1. Evolución de la Balanza de Pagos de México

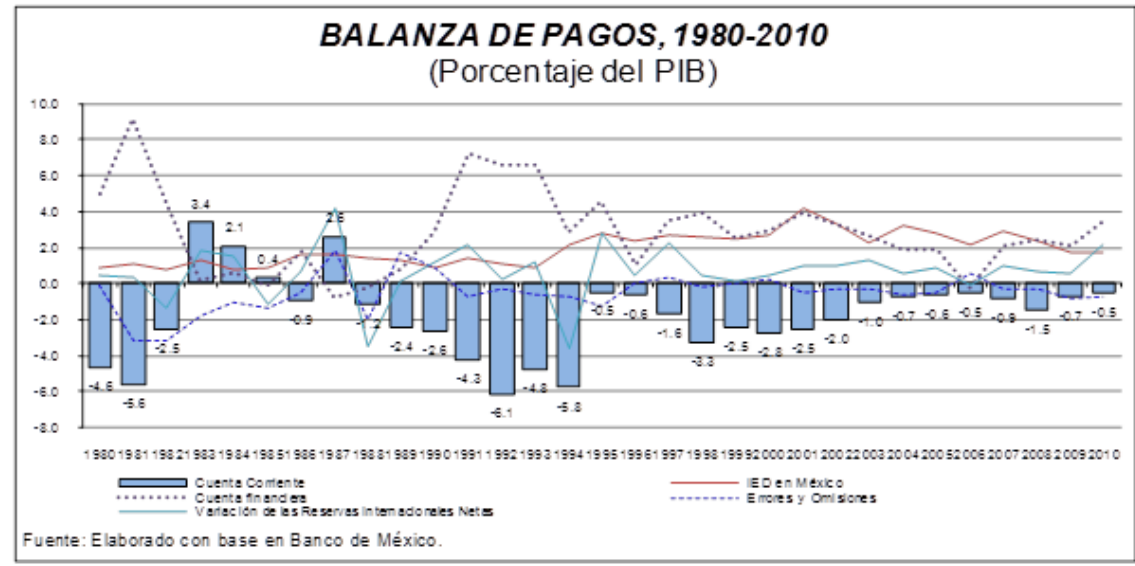

El análisis de los componentes de la BP se realiza primero de 1980-1994 con tipo de cambio fijo o semifijo (deslizamientos) y posteriormente de 1995-2010 cuando el tipo de cambio es flexible, con la finalidad de examinar si existió o no una restricción al crecimiento económico por la dinámica de la $\mathrm{BP}$, que posteriormente se probará a través de la estimación de los modelos.

\subsection{El comportamiento de la Balanza de Pagos en México durante 1980-1994}

El antecedente de la decada de los ochenta presento episodios de crisis (19701982), las cuales dejaron un valioso aprendizaje sobre el tipo de cambio fijo, este no puede sostenerse si se incrementa el deficit fiscal y se pretende financiar con credito primario del Banco Central. Asi, en 1981 el deficit en CC se ubico en $-5.6 \%$ con respecto del PIB, en contraste con $-4.6 \%$ del PIB en 1980 . En 1983-1985 se vivio una experiencia desinflacionaria (por lo que el superavit de la CC fue $3.4 \%, 2.1 \%$ y $0.4 \%$ del PIB para esos anos). En octubre de 1987 se dio el desplome de la Bolsa de Valores y la fuga de capitales que derivo, en noviembre, en una devaluacion, asi para diciembre de ese ano se implemento el programa de estabilizacion, pero ahora con algunos aspectos de corte heterodoxo.

En contraste con la política ortodoxa de estabilización que se implementaba, la cual consistía en el saneamiento de las finanzas públicas y la aplicación de una política monetaria restrictiva. En 1987 se da especial atención a la política de ingresos (la llamada concertación social entre gobierno, empresas y trabajadores), al adelgazamiento del sector público, al comportamiento concertado del tipo de cambio y a la promoción de la apertura comercial como parte de los componentes estructurales. Así, durante 1987-1992 se ejecutó el Pacto o Concertación Social con dos cambios posteriores: el Pacto de Solidaridad Económica y el Pacto para la Estabilidad y el Crecimiento Económico.

En cada fase del pacto se acordaba una regla de política cambiaría como sigue: de diciembre de 1987 a febrero de 1988, un tipo fijo de 2.22 pesos por dólar (política cambiaria para apoyar la desinflación sin sacrificar competitividad); en 
marzo de 1988 un tipo de cambio fijo a la paridad vigente el 29 de febrero de 1998; de enero a julio de 1989 un desliz de 1 peso diario; de agosto de 1989 a marzo de 1990 sigue el desliz de 1 peso diario; de enero a diciembre de 1990 el desliz fue de 80 centavos diarios; de diciembre de 1990 a diciembre de 1991 el desliz fue de 20 centavos diarios; y de diciembre de 1991 a diciembre de 1992 el desliz fue de 40 centavos diarios, obsérvese la gráfica 2 .

Gráfica 2. Tipo de cambio nominal y real promedio 1980-1994
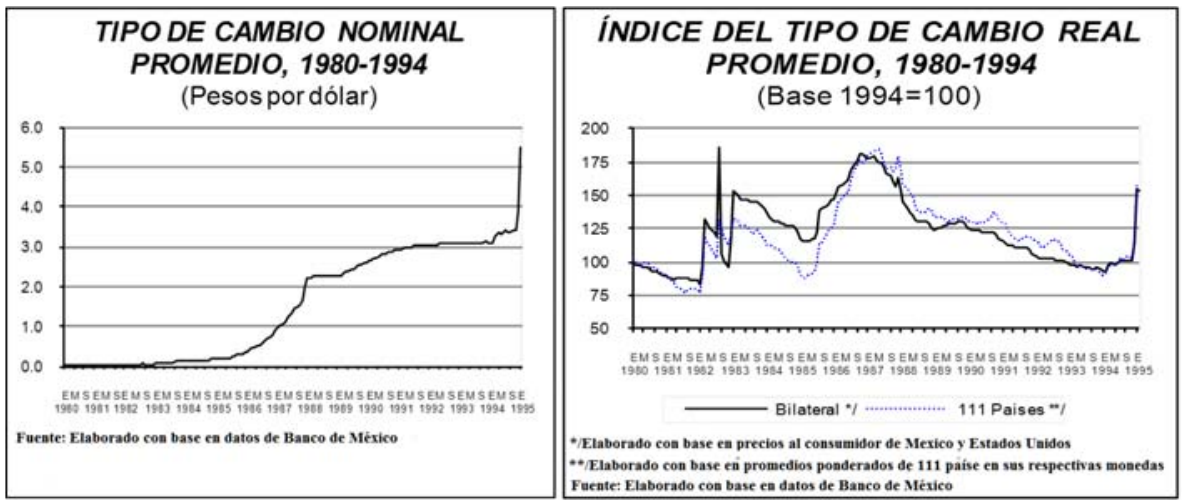

El análisis anterior refleja que se empleaba el tipo de cambio como ancla nominal para sujetar la evolución de los precios y esto se observa con mayor nitidez en el comportamiento del Tipo de Cambio Real (TCR), particularmente cuando el TCR promedio experimentó una apreciación de 33.8\% en el periodo de 1987 a 1991, como se observa en la gráfica 2.

El comportamiento del tipo de cambio refleja dos aspectos importantes de la crisis economica de mediados de 1981: la contraccion en los mercados externos para los productos de exportacion de Mexico y el encarecimiento y menor disponibilidad de credito externo, lo cual influyo en la CC, la cual para 1994 presento el deficit mas alto (-29 mil 662.0 millones de dolares). El segundo deficit mas fuerte se dio en 1992 ( -24 mil 438.5 millones de dolares) y el tercero en 1993 ( -23 mil 399.2 millones de dolares). Durante 1992-1994 se adopto oficialmente un regimen cambiario de bandas, pero este esquema no fue sostenible por la gran entrada de flujos en la cuenta de capital registrandose en 1993 el superavit de la Cuenta de Capital mas alto hasta 2009 (32 mil 341.3 millones de dolares, $22.1 \%$ anual), la tendencia se revirtio en 1994 (14 mil 975.6 millones de dolares, $-53.7 \%$ con respecto de 1993).

A continuación se da un tratamiento particular a 1994, ya que a partir de 1995 se adopta el régimen de tipo de cambio flexible. Las exportaciones e importaciones de mercancías se incrementaron a tasas anuales de $17.3 \%$ y $21.4 \%$, respectivamente. De esta manera, la balanza comercial se incrementó $37.0 \%$ en 1994. 
Gráfica 3. Principales rubros de la Balanza de Pagos 1980-1994
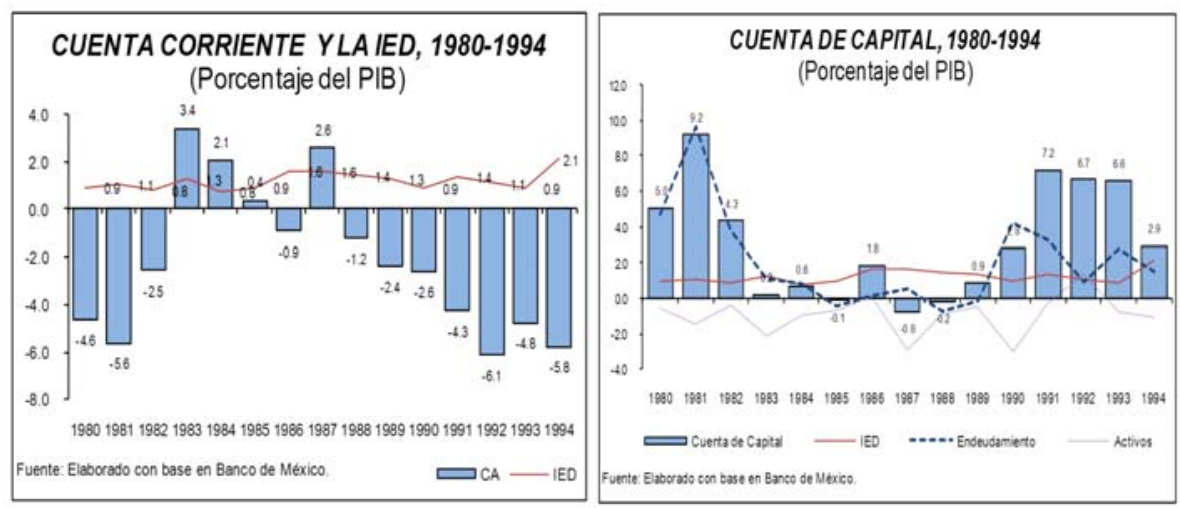

Como se observa en la Grafica 3, en 1994 la CC de la BP tuvo un deficit de 29 mil 662.0 millones de dolares, nivel superior en $26.8 \%$ al observado un año antes ( -23 mil 399.2 millones de dolares). Como porcentaje del PIB este deficit represento $-5.8 \%$, dato superior al del año anterior ( $-4.8 \%)$. Mientras que la cuenta de capital tuvo un superavit de 14 mil 975.6 millones de dolares (un año antes se registro uno de 32 mil 341.3 millones de dolares).

El crecimiento del endeudamiento con el exterior por 7 mil 814.7 millones de dólares fue resultado del endeudamiento de la Banca de Desarrollo (4 mil 381.9 millones de dólares), la Banca Comercial (1 mil 570.7 millones de dólares), del Sector Privado por 3 mil 828.4 millones de dólares y la amortización del Banco de México por 1 mil 203.2 millones de dólares, así como la del Sector Público por 763.1 millones de dólares.

En 1994, la Inversión Extranjera Directa (IED) presentó una entrada neta de 10 mil 972.5 millones de dólares, lo que produjo un crecimiento anual de $150.0 \%$. La inversión extranjera de cartera registró una entrada neta de 1 mil 858.4 millones de dólares, en particular, se registró un ingreso neto en el mercado accionario por 4 mil 83.7 (que contrasta con la entrada de 519.2 millones de dólares en 1995) y una salida en el mercado de dinero por 2 mil 225.3 millones de dólares (13 mil 859.6 millones de dólares en 1995). Por otro lado, los activos en el exterior de los residentes en México se incrementaron en 5 mil 670.0 millones de dólares (un año antes eran de 3 mil 602.5 millones de dólares, lo que implica un crecimiento de $57.4 \%$, y un año después se incrementaron 7 mil 357.7 millones de dólares, lo cual implica un crecimiento del $29.8 \%$ en 1995).

La balanza de servicios factoriales registro un deficit de 13 mil 11.8 millones de dolares, lo que representa un incremento anual de $13.8 \%$. Las utilidades remitidas se expandieron $9.0 \%$ y las reinvertidas $69.1 \%$. El pago neto de intereses fue de 9 mil 107.3 millones de dolares, $2.5 \%$ mayor que el realizado el ano previo (-8 mil 886.4 millones de dolares); como porcentaje del PIB este pago represento el $-1.8 \%$ (ver grafica 4 ). 
Gráfica 4. Principales rubros de la Cuenta Corriente 1980-1994
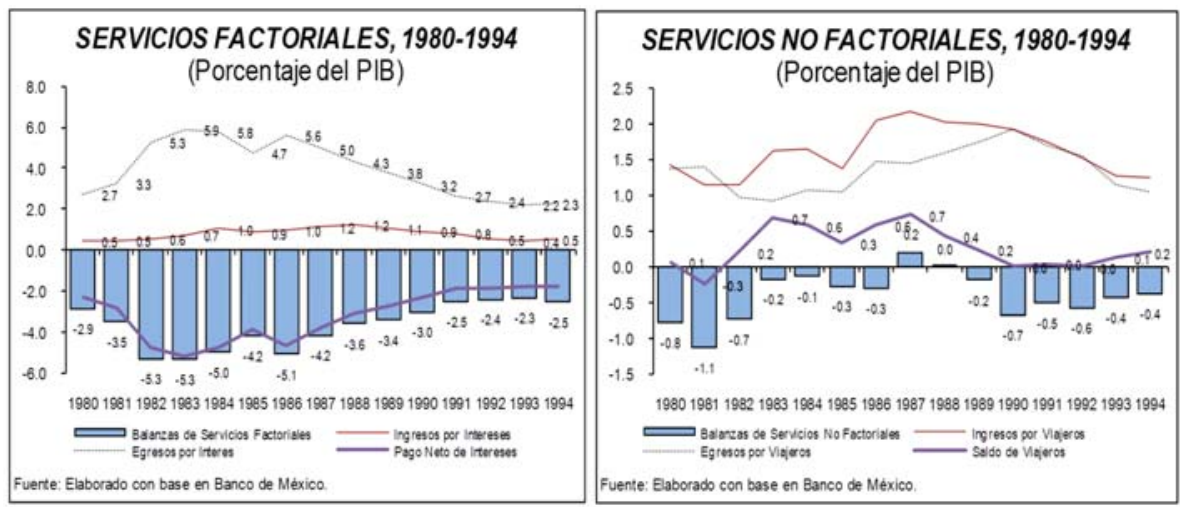

La balanza de servicios no factoriales tuvo un deficit de -1 mil 968.3 millones de dolares, inferior en $7.6 \%$ al registrado en 1993 . El saldo de viajeros presento un superavit de 1 mil 25.8 millones de dolares, saldo que implica un incremento anual de $69.5 \%$ mayor que el de 1993 cuando se registro un superavit de 605.2 millones de dolares, como resultado del aumento de $3.2 \%$ en los ingresos por viajeros y la reduccion de $4.0 \%$ en los egresos por este mismo concepto. Los egresos por fletes se ubicaron en 2 mil 639.8 millones de dolares $21.1 \%$.

Gráfica 5. Transferencias y Reservas Internacionales Netas 1980-1994
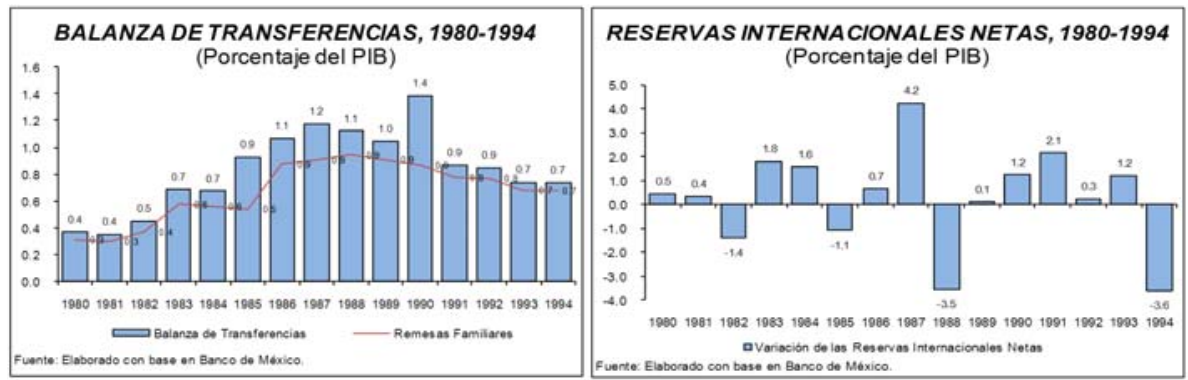

De acuerdo con la gráfica 5, las transferencias netas del exterior fueron de 3 mil 781.9 millones de dólares, cifra superior en $3.9 \%$ a la observada un año antes. Los ingresos por remesas familiares aumentaron en $4.2 \%$ ubicándose en 3 mil 474.7 millones de dólares. En 1994 el déficit en cuenta corriente y el superávit en cuenta de capital, más el flujo negativo de errores y omisiones por 3 mil 705.0 millones de dolares, dieron por resultado una variacion de las reservas internacionales netas por -18 mil 389.3 millones de dolares y un monto de reservas de 6 mil 148.2 millones de dolares. 


\subsection{Análisis de la Balanza de Pagos durante 1995-2010}

Durante 1994 la CC de la BP tuvo el minimo historico comprendido de 19802010, con un deficit de -29 mil 662.0 millones de dolares, al interior la balanza comercial registro un deficit comercial de -18 mil 463.7 millones de dolares. Como porcentaje del PIB estos deficits representaron $-5.8 \%$ y $-3.6 \%$, respectivamente. La balanza de servicios factoriales registro un nivel minimo en 2007 (-18 mil 994.4 millones de dolares); sin embargo al interior los ingresos y egresos reportaron un nivel maximo (7 mil 749.0 millones de dolares y 26 mil 743.4 millones de dolares, correspondientemente).

En 2010, el deficit de la balanza de servicios factoriales fue de -14 mil 462.6 millones de dolares, es decir, tuvo una disminucion anual de $2.4 \%$. Las utilidades remitidas se expandieron en $9.2 \%$ y las reinvertidas se redujeron $36.4 \%$. El pago neto de intereses fue de 8 mil 844.8 millones de dolares, $11.1 \%$ mayor que el realizado el ano previo (-7 mil 959.7 millones de dolares); como porcentaje del PIB este pago constituyo $-0.9 \%$. La balanza de servicios no factoriales tuvo un maximo en 1995 de 664.5 millones de dolares, que contrasta con el deficit de 1994 ( -1 mil 968.3 millones de dolares).

Mientras que el maximo registrado en ingresos y egresos de la balanza de servicios no factoriales se dio en 2008 con 18 mil 39.9 millones de dolares y 25 mil 419.2 millones de dolares, respectivamente. En contraste, el minimo registrado en la balanza de servicios no factoriales se registro en 2010 (-9 mil 610.9 millones de dolares). En 2010, el saldo de viajeros presento un superavit de 4 mil 588.4 millones de dolares, saldo que implica un incremento anual de 10.7 (4 mil 143.5 millones de dolares en 2009), como resultado del aumento de $5.3 \%$ y $2.1 \%$ en los ingresos y egresos por viajeros, respectivamente. Los egresos por fletes se ubicaron en 8 mil 723.2 millones de dolares $16.2 \%$ con respecto de 2009 (7 mil 509.8 millones de dolares).

Las transferencias netas del exterior en 2007 fueron de 26 mil 395.8 millones de dólares, registrando un nivel máximo en gran parte por el nivel record de los ingresos en este rubro (26 mil 503.5 millones de dólares) y el nivel máximo de los egresos por transferencias se dio en 2008 (128.2 millones de dólares). En 2010 las transferencias netas registraron 21 mil 504.2 millones de dólares.

Los ingresos por remesas familiares (21 mil 271.2 millones de dólares) aumentaron $0.1 \%$, después de haber presentado disminuciones anuales de $15.5 \%$ y $3.5 \%$, en 2009 y 2008 , respectivamente. Asimismo, en 2010 el déficit en cuenta corriente y el superávit en cuenta de capital (36 mil 16.8 millones de dólares), más el flujo negativo de errores y omisiones por 7 mil 647.2 millones de dólares,

dieron por resultado una variación de las reservas internacionales netas por 22 mil 758.7 millones de dólares y un monto de 113 mil 596.5 millones de dólares. 
Gráfica 6. Tipo de cambio nominal y real promedio 1995-2010

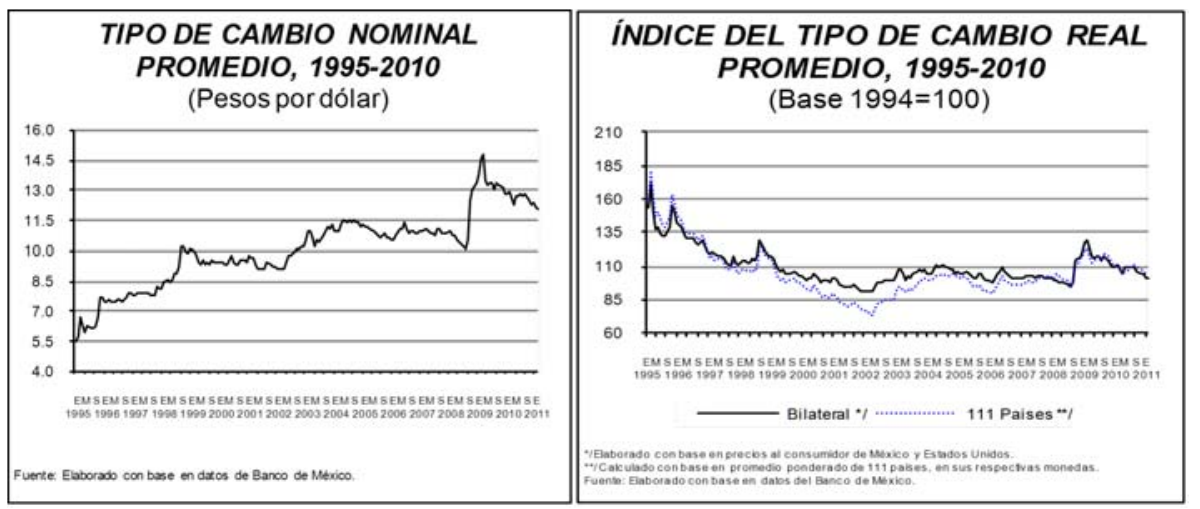

Este análisis refleja que la flotación intervenida del tipo de cambio permitió mayor flexibilidad a la política económica, lo cual se observa mejor en el comportamiento del Tipo de Cambio Real (TCR), cuando el TCR promedio experimentó una apreciación de $25.7 \%$ en el periodo de 1995 a 2010, como se observa en la gráfica 6 .

3.3 Análisis de la Balanza de Pagos en la nueva presentación en 2010 En esta sección se analiza a la BP de acuerdo a la última presentación acorde con la quinta edición del Manual de BP del FMI, publicada por Banco de México a partir del segundo trimestre de 2010.

En el comparativo anual, en 1995 la cuenta corriente registró el mayor superávit de la balanza de bienes ( 7 mil 6.3 millones de dólares) y de la balanza de servicios (31.9 millones de dólares) llevando a un superávit en la balanza de bienes y servicios por 7 mil 38.2 millones de dólares. Resaltando un máximo histórico en la CC con un déficit de 1 mil 576.7 millones de dólares. Sin embargo, durante 1995 se registraron mínimos históricos en las exportaciones e importaciones de bienes (por 79 mil 637.6 millones de dólares y 72 mil 631.3 millones de dólares), así como en los ingresos y egresos de servicios (9 mil 569.0 millones de dólares y 9 mil 537.2 millones de dólares). Otros mínimos históricos del periodo de 1995-2010 se registraron en 1995, para los ingresos de la balanza de renta por 3 mil 827.7 y en las transferencias netas por 3 mil 959.9 millones de dólares (al interior ingresos por 3 mil 995.0 millones de dólares).

En 2000, se registro el minimo historico de la cuenta corriente (-18 mil 742.7 millones de dolares) y en 2001 de los egresos por transferencias (21.9 millones de dolares). En 2004 el maximo de la balanza de renta (-9 mil 364.9 millones de dolares) con un minimo en ingresos de este rubro por 15 mil 73.3 millones de dolares.

Para 2007 se presentan máximos en ingresos y egresos (7 mil 749.0 y 26 mil 473.4 millones de dólares), además de máximos en las transferencias netas y en sus ingresos (26 mil 395.8 y 26 mil 503.5 millones de dólares). En 2008 el máximo de los ingresos y egresos de la cuenta corriente (342 mil 539.1 y 358 mil 888.3 millones de dólares). Además se registran el máximos histórico de las importaciones de bienes, los ingresos por servicios y los egresos por transferencias (309 mil 500.9, 17 mil 497.4 y 128.2 millones de dólares). 


\section{Nueva Época REMEF (The Mexican Journal of Economics and Finance)}

En tanto que en 2010 se dio el maximo de las exportaciones de bienes y los egresos por servicios (298 mil 769.2 millones de dolares y 25 mil 263.6 millones de dolares), en contraste con el deficit reportado en la balanza de servicios (-10 mil 229.0 millones de dolares). De esta manera, en 2010 la cuenta corriente de la BP acumulo un deficit de 5 mil 690.0 millones de dolares, inferior en 599.3 millones de dolares $(9.5 \%$ ) al observado en 2009. Con respecto del PIB, el deficit acumulado fue equivalente a $0.5 \%$, la menor proporcion desde 2006 .

En 2010 el deficit de bienes (balanza que incluye la balanza de mercancias generales, antes la balanza comercial, mas la balanza de bienes adquiridos en puertos por medios de transporte) registro un deficit de 3 mil 50.5 millones de dolares (deficit de 4 mil 846.1 millones de dolares en 2009). La balanza de mercancias generales presento un deficit de -3 mil 120.7 millones de dolares (-4 mil 601.9 millones de dolares en 2009). Mientras que la balanza de bienes adquiridos en puertos por medio de transporte tuvo un superavit de 70.2 millones de dolares, que contrasta con el deficit en 2009 ( -244.1 millones de USD).

Gráfica 7. Principales rubros de la Balanza de Pagos 1995-2010

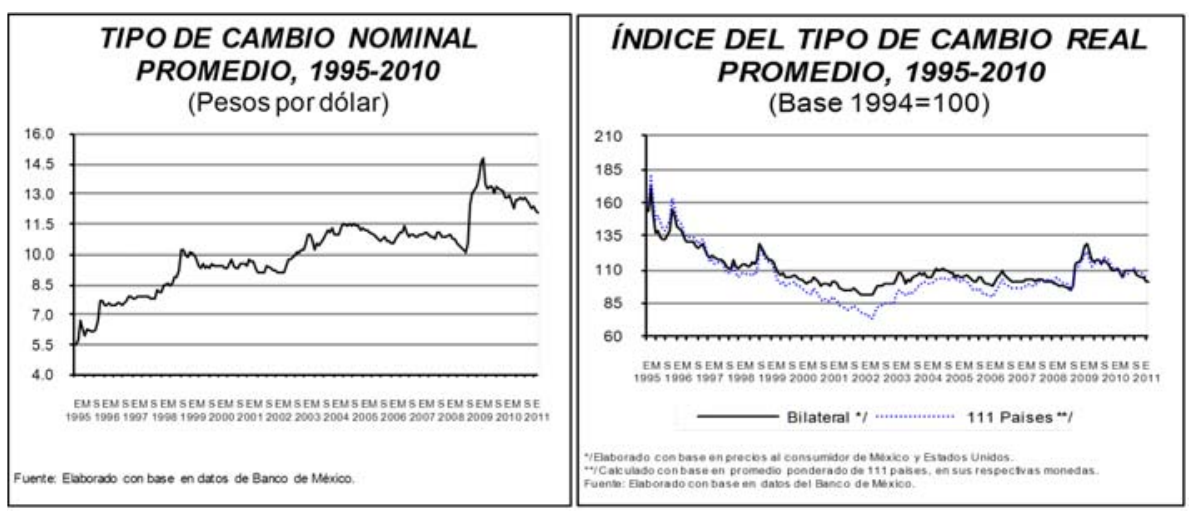

Con base en la gráfica 7 se observa que en 2010 la cuenta financiera tuvo un superávit de 33 mil 942.1 millones de dólares, superior en $89.4 \%$ al presentado en 2009 (superávit de 17 mil 919.3 millones de dólares). La inversión extranjera en México para 2010 fue de 17 mil 725.9 millones de dólares; así la inversión extranjera neta fue de 5 mil 31.8 millones de dólares y la inversión de cartera neta fue de 39 mil 410.9 millones de dólares. En otras inversiones se reportó una salida de 10 mil 5005.5 millones de dólares. Esta evolución se debió, en gran parte, al incremento de los pasivos del sector público y privado por 5 mil 477.7 y 6 mil 693.5 millones de dólares. Además del incremento de los activos en el exterior de los residentes en México por 22 mil 671.8 millones de dólares.

La balanza, en 2010, de servicios tuvo un deficit de -10 mil 229.0 millones de dolares, superior en 1 mil 648.9 millones de dolares al registrado un ano antes. Este crecimiento se debe, principalmente, al incremento anual de $16.2 \%$ en los egresos por fletes y seguros (8 mil 723.2 millones de dolares), lo cual esta relacionado con la aceleracion del comercio exterior. Por otro lado, la balanza turistica presento un superavit de 4 mil 588.4 millones de dolares, saldo que implica un crecimiento anual de $10.7 \%$ (-13.0\% en 2009), como resultado del 
aumento de $5.3 \%$ en los ingresos por viajeros y el crecimiento de $2.1 \%$ en los egresos por este mismo concepto.

Gráfica 8. Principales rubros de la Cuenta Corriente 1995-2010

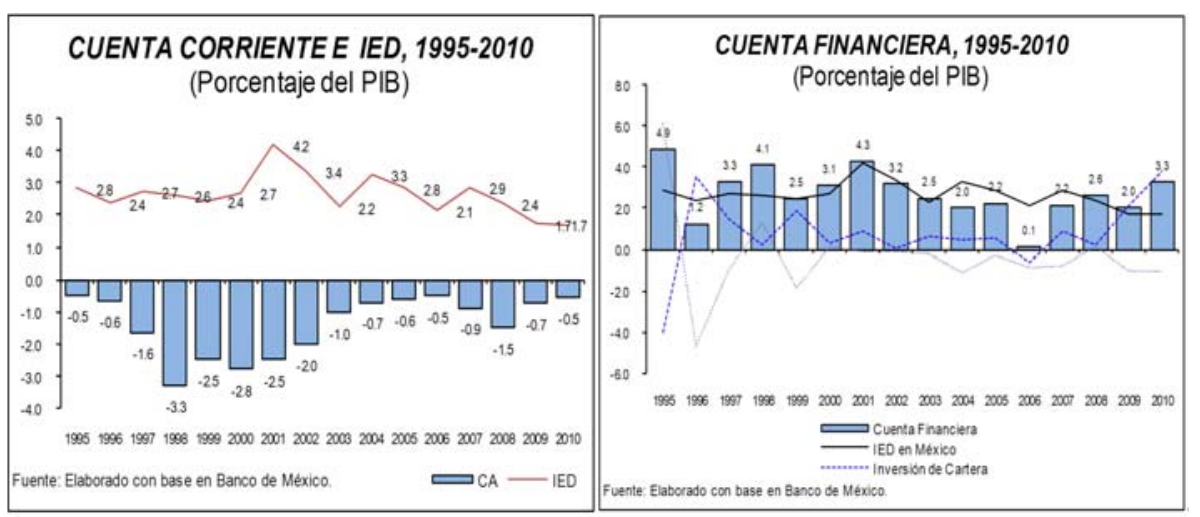

En 2010, la balanza de renta registró un déficit de 13 mil 914.7 millones de dólares, es decir, tuvo una disminución anual de 3.3\% (-15.6\% en 2009). Las utilidades remitidas crecieron $(9.2 \%)$ y las utilidades reinvertidas disminuyeron $(36.4 \%)$, respectivamente. Por su parte, el pago neto de intereses fue de 8 mil 844.8 millones de dólares, mayor en $11.1 \%$ al realizado un año antes; como porcentaje del PIB éste pago representó $-0.9 \%$, véase la gráfica 8 .

Las transferencias netas en 2010 del exterior fueron de 21 mil 504.2 millones de dólares, cifra inferior en $0.1 \%$ a la observada un año antes (21 mil 531.2 millones de dólares) como se observa en la gráfica 9. Los ingresos por remesas familiares aumentaron en 26.5 millones de dólares ubicándose en 21 mil 271.2 millones de dólares (21 mil 244.7 millones de dólares en 2009).

Durante 2010 el déficit en cuenta corriente y el superávit en cuenta financiera, más el flujo negativo de errores y omisiones por 7 mil 636.8 millones de dólares, dieron por resultado una variación de reservas internacionales brutas por 20 mil 694.5 millones de dólares. Al cierre de 2010 las reservas internacionales netas ascendieron a 113 mil 596.5 millones de dólares.

\subsection{Actualizaciones de la Balanza de Pagos en 2010}

Para el cierre de 2010, se hicieron revisiones de cifras de algunos renglones de la BP. Para la cuenta corriente las modificaciones fueron menores y abarcaron desde 2005 (particularmente mayores egresos acumulados de las balanzas de servicios y renta por 147.8 y 407.2 millones de dólares, respectivamente), mientras que la cuenta financiera se modificó a partir de 1999 por mayores niveles acumulados de inversión extranjera directa en México por 5 mil 259.5 millones de dólares hasta el 3er trimestre de 2010.

En el comparativo para el último trimestre de 2010 en la cuenta corriente se registró: un mayor déficit de la balanza de bienes ( 1 mil 52.4 vs. 39.6 millones de dólares); un mayor déficit en la balanza de servicios en 20.6\% (3 mil 143.0 vs. 2 mil 605.8 millones de dólares); el mayor déficit en la balanza de renta en $66.2 \%$ (4 mil 568.0 vs. 2 mil 747.9 millones de dólares) y un mayor superávit de transferencias en $5.9 \%$ (5 mil 137.0 vs. 4 mil 849.9 millones de dólares). 


\subsection{Conclusiones derivadas del análisis estadístico de los datos}

En la primera primera parte de la investigación se llevó a cabo un análisis sobre la dinámica de la BP y el crecimiento económico, este análisis es fundamental porque refleja la estructura de la economía en el corto y largo plazos, así como sus ciclos y aspectos coyunturales. Asimismo, se realizó una revisión de la literatura empírica del comportamiento de la BP en diferentes economías latinoamericanas. Por otro lado, con base en el EMBP, se discutió sobre la evidencia en pequeñas economías con tipos de cambio fijo de la funcionalidad de la ecuación de flujo de reserva. No obstante, en el caso de economías con tipo de cambio flotante, dado en (4), se tienen otras implicaciones sobre la BP, las cuales se fueron destacadas para, posteriormente, realizar el análisis detallado de los datos. El EMBP es un marco de referencia apropiado para el análisis de política en un sistema de tipo de cambio fijo, porque en el largo plazo se presenta un proceso de ajuste automático y no hay requerimientos de política. No obstante, los países en desarrollo bajo sistemas de tipo de cambio fijo no pueden mantener la cantidad de dinero necesaria durante mucho tiempo, como en México a finales de 1994 cuando se optó por un tipo de cambio flotante dado que el nivel de las Reservas Internacionales se volvió insostenible.

Ahora bien, con respecto del comportamiento del tipo de cambio flotante éste puede afectar el control de la inflación. De esta manera, una política monetaria restrictiva puede ayudar a mantener o restaurar el equilibrio en los precios y así crear las condiciones de estabilidad para el mejor desempeño de la BP. Otra forma de alcanzar una mejor situación en la CC de la BP es el incremento de las exportaciones, pero esto aumentaría la inflación si no se conjuga con otras políticas económicas.

Por lo anterior, se sugieren políticas estructurales que mejoren la competitividad. Los resultados de esta investigación muestran que la teoría asienta que una economía pequeña y con un alto grado de apertura no necesariamente genera un efecto inflacionario, sino que un aumento en la capacidad de compra se puede traducir en mayores importaciones, las cuales disminuirán el nivel de reservas monetarias internacionales. Así, mientras se disponga de suficientes reservas no habrá efecto alguno sobre el nivel general de precios. Lo anterior señala un enfoque útil para el análisis de la dinámica de la inflación en economías pequeñas y abiertas. Además, si la economía posee un sistema financiero suficientemente desarrollado, el exceso de liquidez generará una reducción de las tasas de interés.

Es importante destacar que los resultados obtenidos en esta investigación muestran que durante las últimas décadas la dinámica de la balanza de pagos en México ha influido de forma positiva al crecimiento económico de México; sin embargo, aún puede mejorarse la competitividad a través del incremento de la capacidad productiva, por lo que es necesaria una política industrial.

Por último, como se comentó al inicio de la presente investigación, el planteamiento, la estimación y la interpretación de los resultados de los modelos dinámicos propuestos se efectuará en la parte II, Es importante resaltar que la metodología de estimación de los modelos dinámicos en la segunda parte de esta investigación corresponde a la utilizada en la mayoría de aplicaciones sobre el tema en cuestión en América Latina (las funciones de impulso respuesta se interpretan desde el modelo VAR estructural y el modelo 
VEC proporciona la ecuación de cointegración que puede interpretarse como la relación de equilibrio entre las distintas variables que conforman el modelo). No obstante, existen otras alternativas para analizar las respuestas a los impulsos a partir de la estimación del VECM. De esta manera se determinan, primero, las características del espacio de cointegración y, posteriormente, se lleva a cabo el análisis de impulso-respuesta.

\section{Apéndice 1. Balanza de pagos 2008-2010}

\begin{tabular}{|c|c|c|c|c|c|c|c|c|c|c|c|c|}
\hline \multicolumn{13}{|c|}{$\begin{array}{l}\text { Cuadro 5. BP, 2008-2010*/ } \\
\text { Miles de millones de dólares }\end{array}$} \\
\hline & \multicolumn{4}{|c|}{2008} & \multicolumn{4}{|c|}{2009} & \multicolumn{4}{|c|}{2010} \\
\hline & I & II & III & IV & I & II & III & IV & I & II & III & IV \\
\hline Cuenta Corriente & -3.0 & -2.2 & -4.3 & -6.8 & -1.9 & -0.2 & -3.6 & -0.5 & 0.5 & -0.7 & -1.9 & -3.6 \\
\hline Balanza bienes y serv icios & -2.5 & -3.0 & -9.0 & -10.4 & -3.6 & -1.6 & -5.6 & -2.6 & -1.0 & -2.7 & -5.4 & -4.2 \\
\hline Balanza de bienes $1 /$ & -1.7 & -1.0 & -6.5 & -8.4 & -2.3 & 0.4 & -2.9 & 0.0 & 0.3 & -0.1 & -2.2 & -1.1 \\
\hline Exportaciones & 70.2 & 79.6 & 78.6 & 63.5 & 49.7 & 54.1 & 58.6 & 67.7 & 66.7 & 74.8 & 75.6 & 81.7 \\
\hline Importaciones & 71.9 & 80.5 & 85.2 & 71.9 & 52.1 & 53.7 & 61.5 & 67.7 & 66.4 & 74.8 & 77.9 & 82.7 \\
\hline Balanza de servicios & -0.7 & -2.0 & -2.4 & -2.0 & -1.3 & -2.0 & -2.7 & -2.6 & -1.3 & -2.6 & -3.2 & -3.1 \\
\hline Ingresos & 4.9 & 4.4 & 4.1 & 4.1 & 4.4 & 3.2 & 3.2 & 3.7 & 4.5 & 3.7 & 3.4 & 3.5 \\
\hline Egres & 5.7 & 6.4 & 6.5 & 6.1 & 5.7 & 5.1 & 6.0 & 6.3 & 5.8 & 6.3 & 6.6 & 6.6 \\
\hline Balanza de renta & -6.4 & -6.2 & -1.9 & -2.6 & -3.9 & -4.3 & -3.5 & -2.7 & -3.4 & -3.9 & -2.1 & -4.6 \\
\hline Ingresos & 2.0 & 2.1 & 1.8 & 1.7 & 1.6 & 1.3 & 1.3 & 1.0 & 2.0 & 1.1 & 1.1 & 1.2 \\
\hline Egresos & 8.4 & 8.3 & 3.7 & 4.3 & 5.5 & 5.6 & 4.7 & 3.8 & 5.4 & 5.0 & 3.2 & 5.7 \\
\hline Transferencias netas & 5.9 & 6.9 & 6.5 & 6.2 & 5.5 & 5.7 & 5.4 & 4.8 & 4.9 & 5.9 & 5.6 & 5.1 \\
\hline Cuenta financiera $2 /$ & 8.0 & 2.9 & 10.6 & 7.1 & -6.1 & -1.0 & 11.7 & 13.4 & 5.0 & 4.6 & 10.4 & 13.9 \\
\hline Inversión directa & 7.5 & 6.4 & 4.9 & 5.9 & 1.0 & 5.4 & 0.9 & 0.9 & 2.1 & 0.3 & 1.3 & 1.3 \\
\hline En México & 7.0 & 7.5 & 4.8 & 6.5 & 4.6 & 5.8 & 2.1 & 2.8 & 4.9 & 7.6 & 2.4 & 2.8 \\
\hline De mexicanos en el ex terior & 0.5 & -1.1 & 0.1 & -0.7 & -3.5 & -0.4 & -1.2 & -1.8 & -2.8 & -7.3 & -1.1 & -1.4 \\
\hline Inversión de cartera & 3.0 & 5.3 & 0.1 & -5.7 & -2.0 & 1.1 & 8.9 & 11.2 & 10.2 & 4.1 & 12.8 & 12.3 \\
\hline Pasivos & 4.2 & 5.8 & 0.6 & -5.8 & -1.2 & 1.0 & 7.8 & 7.6 & 9.8 & 6.2 & 9.6 & 11.6 \\
\hline ector público 3 / & 5.6 & 3.8 & 5.1 & -3.5 & -1.5 & 0.5 & 5.7 & 4.5 & 6.2 & 0.7 & 9.5 & 11.7 \\
\hline Sector privado & -1.4 & 1.9 & -4.5 & -2.3 & 0.3 & 0.5 & 2.0 & 3.1 & 3.6 & 5.4 & 0.2 & -0.2 \\
\hline Activos & -1.3 & -0.5 & -0.4 & 0.1 & -0.9 & 0.1 & 1.1 & 3.5 & 0.4 & -2.0 & 3.2 & 0.7 \\
\hline Otra in & -2.5 & -8.8 & 5.5 & 6.9 & -5.1 & -7.5 & 1.9 & 1.3 & -7.2 & 0.2 & -3.7 & 0.3 \\
\hline Pasivos & 1.5 & -0.1 & 4.6 & -0.1 & 0.0 & 0.3 & 3.4 & 2.9 & -2.7 & 0.7 & 1.7 & 12.5 \\
\hline Sector público & 1.1 & -0.6 & 1.1 & 2.3 & 1.5 & -0.7 & 0.9 & 2.9 & 0.1 & 1.5 & -1.7 & 8.8 \\
\hline Banco de México & 0.0 & 0.0 & 0.0 & 0.0 & 0.0 & 3.2 & 4.0 & 0.0 & -3.2 & 0.0 & 0.0 & 0.0 \\
\hline Sector privado & 0.5 & 0.6 & 3.5 & -2.4 & -1.5 & -2.2 & -1.6 & 0.0 & 0.5 & -0.8 & 3.3 & 3.7 \\
\hline Activos & -4.0 & -8.7 & 1.0 & 7.0 & -5.1 & -7.8 & -1.4 & -1.6 & -4.5 & -0.5 & -5.4 & -12.2 \\
\hline Errores y omisiones & -1.1 & 2.3 & -1.4 & -3.8 & -1.6 & -2.9 & -1.7 & -0.8 & -3.8 & 0.0 & -0.4 & -3.4 \\
\hline Variación de la reserv & 3.9 & 2.9 & 4.8 & -3.6 & -9.7 & -4.2 & 6.3 & 12.1 & 1.7 & 4.0 & 8.1 & 6.9 \\
\hline Ajustes por valora ción & 0.0 & 0.0 & 0.0 & 0.0 & 0.0 & 0.0 & 0.0 & 0.0 & 0.0 & 0.0 & 0.0 & 0.0 \\
\hline \multicolumn{13}{|c|}{$\begin{array}{l}\text { */ Presentación acorde con la quinta edición del Marual de BP del FMI, publicada por Banco de México a partir del segundo trimestre } \\
\text { de } 2010 \text {. } \\
1 \text { Induye la balanza de mercancias generales (antes la balanza comercial) más la balanza de bienes adquiri dos en puertos por medios de } \\
\text { transporte. } \\
2 \text { / A partir del primer trimestre de } 2009 \text {, el financiamiento externo a proyectos Pidiregas se registra como parte del endeudamiento del } \\
\text { Sector Publico No Bancario. } \\
\text { 3/ Incluye proyectos Pidiregas. } \\
\text { 4/ Induye proyectos Pidiregas y excluye Banco de México. } \\
\text { Fuente: Elaboración propia con datos del Banco de México. }\end{array}$} \\
\hline
\end{tabular}




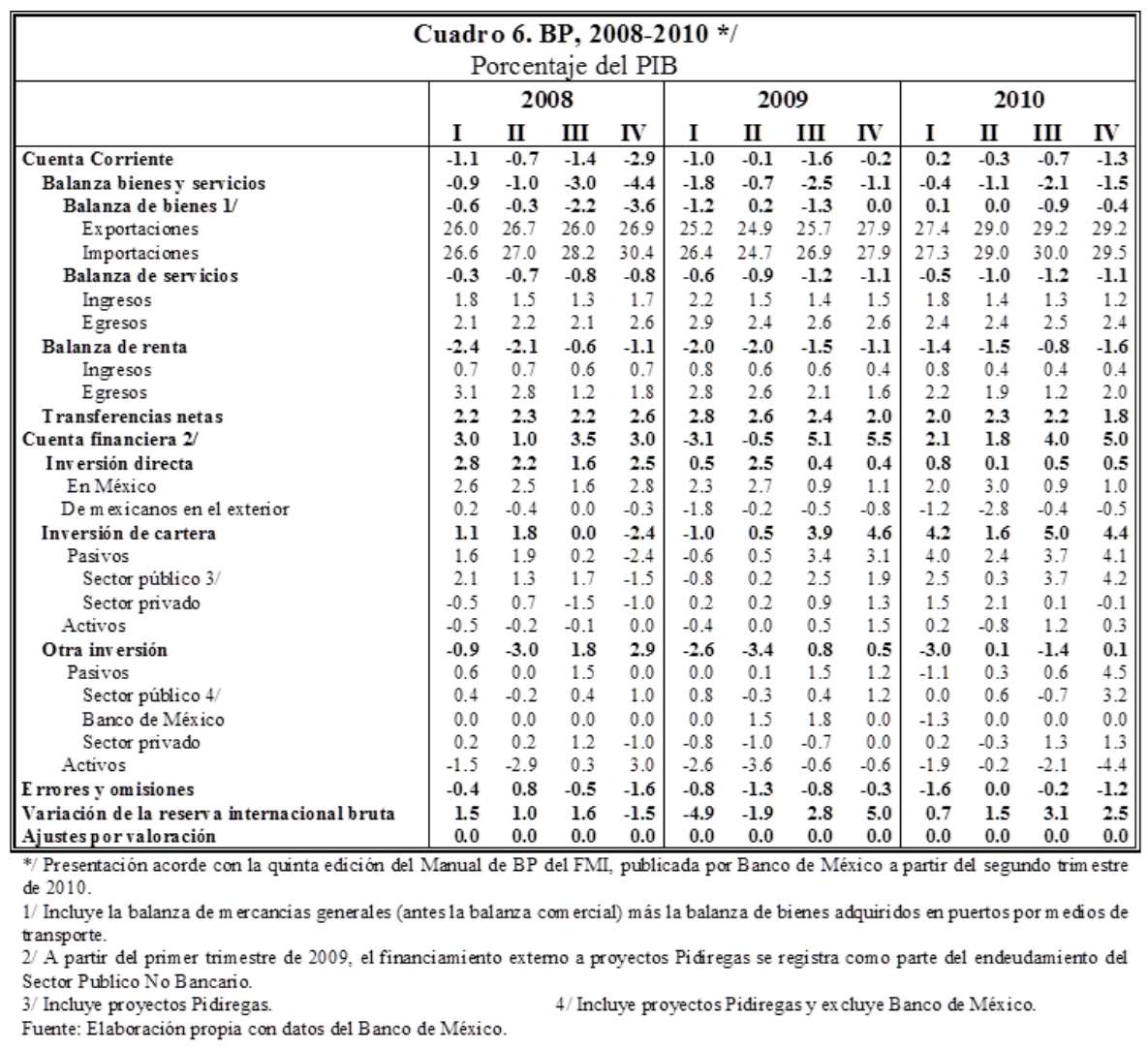




\begin{tabular}{|c|c|c|c|c|c|c|}
\hline \multicolumn{7}{|c|}{ Cuadro 7. BP, 2008-2010 */ } \\
\hline & \multicolumn{3}{|c|}{ Miles de millones de dólares } & \multicolumn{3}{|c|}{$\%$ del PIB } \\
\hline & 2008 & 2009 & 2010 & 2008 & 2009 & 2010 \\
\hline Cuenta Corriente & -16.3 & -6.3 & -5.7 & -1.5 & -0.7 & -0.5 \\
\hline Balanza bienes y servicios & -24.8 & -13.4 & -133 & -2.3 & -1.5 & -1.3 \\
\hline Balanza de bienes 1/ & -17.6 & -4.8 & -3.1 & -1.6 & -0.5 & -0.3 \\
\hline Exportaciones & 291.9 & 230.1 & 298.8 & 26.6 & 26.1 & 28.7 \\
\hline Importaciones & 309.5 & 234.9 & 301.8 & 28.2 & 26.6 & 29.0 \\
\hline Balanza de servicios & -7.1 & -8.6 & -10.2 & -0.7 & -1.0 & -1.0 \\
\hline Ingresos & 17.5 & 14.5 & 15.0 & 1.6 & 1.6 & 1.4 \\
\hline Egresos & 24.6 & 23.1 & 253 & 2.2 & 2.6 & 2.4 \\
\hline Balanza de renta & -17.1 & -14.4 & -13.9 & -1.6 & -1.6 & -1.3 \\
\hline Ingresos & 7.6 & 5.3 & 5.4 & 0.7 & 0.6 & 0.5 \\
\hline Egresos & 24.6 & 19.7 & 19.3 & 2.2 & 2.2 & 1.9 \\
\hline Transferencias netas & 25.5 & 21.5 & 21.5 & 2.3 & 2.4 & 2.1 \\
\hline Cuenta financiera $2 /$ & 28.5 & 17.9 & 33.9 & 2.6 & 2.0 & 3.3 \\
\hline Inversión directa & 24.7 & 8.2 & 5.0 & 2.3 & 0.9 & 0.5 \\
\hline $\begin{array}{l}\text { En México } \\
\text { Enta }\end{array}$ & 25.9 & $\begin{array}{l}8.2 \\
15.2\end{array}$ & $\begin{array}{l}5.0 \\
17.7\end{array}$ & 2.4 & $\begin{array}{l}0.9 \\
1.7\end{array}$ & $\begin{array}{l}0.5 \\
1.7\end{array}$ \\
\hline De mexicanos en el exterior & -1.2 & -7.0 & -12.7 & -0.1 & -0.8 & -1.2 \\
\hline Inversión de cartera & 2.7 & 19.1 & 39.4 & 0.2 & 2.2 & 3.8 \\
\hline Pasivos & 4.8 & 15.2 & 37.1 & 0.4 & 1.7 & 3.6 \\
\hline Sector público 3/ & 11.1 & 9.3 & 28.1 & 1.0 & 1.1 & 2.7 \\
\hline Sector privado & -6.2 & 5.9 & 9.0 & -0.6 & 0.7 & 0.9 \\
\hline Activos & -2.1 & 3.8 & 2.3 & -0.2 & 0.4 & 0.2 \\
\hline Otra inversión & 1.1 & -9.4 & -10.5 & 0.1 & -1.1 & -1.0 \\
\hline $\begin{array}{l}\text { Pasivos } \\
\text { Paur }\end{array}$ & 5.9 & 6.5 & 12.2 & 0.5 & 0.7 & $\begin{array}{l}1.0 \\
1.2\end{array}$ \\
\hline Sector público 4/ & 3.8 & 4.6 & 8.7 & 0.3 & 0.5 & 0.8 \\
\hline Banco de México & 0.0 & 7.2 & -3.2 & 0.0 & 0.8 & -0.3 \\
\hline Sector privado & 2.1 & -5.3 & 6.7 & 0.2 & -0.6 & 0.6 \\
\hline Activos & 4.8 & -15.9 & -22.7 & -0.4 & -1.8 & -2.2 \\
\hline Errores y omisiones & -4.1 & $\begin{array}{l}-1.9 \\
-7.1\end{array}$ & $\begin{array}{l}-2.7 \\
-7.6\end{array}$ & $\begin{array}{ll}-0.4 \\
-0.4\end{array}$ & $\begin{array}{l}-1.0 \\
-0.8\end{array}$ & -0.7 \\
\hline Var.de la reserva internacional bruta & 8.1 & 4.6 & 20.7 & 0.7 & 0.5 & 2.0 \\
\hline $\begin{array}{l}\text { Ajustes por valoración } \\
\text {. }\end{array}$ & 0.0 & -0.1 & -0.1 & 0.0 & 0.0 & 0.0 \\
\hline \multicolumn{7}{|c|}{ 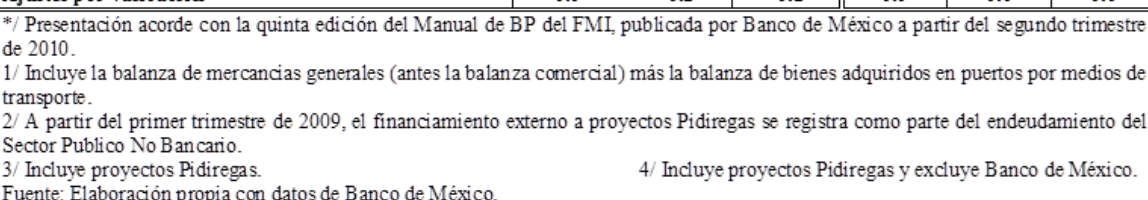 } \\
\hline
\end{tabular}




\section{Bibliografía}

Aghevli, B. B. and M. S. Khan (1977). The Monetary Approach to Balance of Payments Determination: An Empirical Test. In International Monetary Fund (eds.). The Monetary Approach to the Balance of Payments. Washington, DC: IMF.

Arevilca, B. y A. Risso (2007): El Modelo de Crecimiento Restringido por Balanza de Pagos. Evidencia Empírica para Bolivia, 1953-2002, Revista Venezolana de Análisis de Coyuntura, enero-junio, No. 001, pp. 203-231.

Britto, G. (2008): Thirlwalls Law and the Long-Term Equilibrium Growth Rate: An Application for Brazil (1951-2006). Cambridge, Centre for Economic and Public Policy, June.

Coppin, A. (1994). The Determinants of International Reserves in Barbados: A Test of the Monetarist Approach. Journal of Social and Economic Studies, 43(2), pp. 75-89.

Clarida, R., J. Galí, and M. Gertler (2000). Monetary Policy Rules and Macroeconomic Stability: Evidence and Some Theory. Quarterly Journal of Economics, 115(1), pp. 147-180.

Dornbusch, R. (1971). Notes on Growth and the Balance of Payments. Canadian Journal of Economics, 4( 3), pp. 389-395.

Du Plessis, S. P. J, B. W. Smith, and C. L. McCarthy (1998). International Economics (Second edition). Johannesburg: Heinemann.

Engle, R. F., and C. W. J. Granger (1987). Co-Integration and Error Correction Representations, Estimation, and Testing. Econometrica, 55(2), pp. 251-276.

Fugarolas, G. y D. Matesanz (2005). Restricción de Balanza de Pagos y Vulnerabilidad Externa en la Argentina de los Noventa. Un Análisis de Caso. Munich Personal, No. 210. http:// mpra.ub.uni-muen-chen.de/210/

García, M. y A. Quevedo (2005). Crecimiento económico y balanza de pagos: evidencia empírica para Colombia. Cuadernos de Economía, 24(43), pp. 83-104.

Gonzaga, F. (2003). Balance-of-Payments-Constrained Economic Growth in Brazil. Brazilian Journal of Political Economy, 23(1), pp. 62-84.

Frenkel, J. A. (1971). A Theory of Money, Trade and the Balance of Payments in a Model of Accumulation. Journal of International Economics, 1(2), p. 158-187.

Frenkel. J. A. (1981). Flexible Exchange Rates, Prices and the Role of News: Lessons from the 197Os. Journal of Political Economy, Vol. 89, No. 4, pp. 665-705.

García, M. y A. Quevedo (2005). Crecimiento Económico y Balanza de Pagos: Evidencia Empírica para Colombia, Cuadernos de Economía, 24(43), pp. 83-104.

Gonzaga, F. (2003). Balance-of-payments-constrained economic growth in Brazil. Brazilian Journal of Political Economy, 23(1), pp.62-84.

Frenkel, J. A. (1971). "A Theory of Money, Trade and the Balance of Payments in a Model of Accumulation". Journal of International Economics, Vol. 1, No. 2, p. 158-187.

Frenkel. J. A. (1981). Flexible Exchange Rates, Prices and the Role of 'News': Lessons from the 197Os. Journal of Political Economy, 89(4), pp. 665-705.

Howard, M and N. Mamingi (2002). The Monetary Approach to the Balance of Payments: An Application to Barbados. The Singapore Economic Review, 47(2), pp. 213-228.

Johansen, S. (1998). Statistical Analysis of Co-integration Vectors. Journal of Economic Dynamic and Control, 12(2-3), pp. 231-254

Johnson, H. G. (1977a). The Monetary Approach to the Balance of Payments. Journal of International Economics, 7(3), pp. 231-249.

Johnson, H. G. (1977b). The Monetary Approach to the Balance of Payments: A NonTechnical Guide. Journal of International Economics, 7(3), pp. 251-268.

Johnson, H. G. (1972). The Monetary Approach to Balance of Payments Theory. Journal of Financial and Quantitative Analysis, 7(2), pp. 1555-1572.

Juselius, K. (2006). The Cointegrated VAR Model. Methodology and Applications. Advance Text in Econometrics, Oxford University Press.

Laffer, A. B. (1969). The US Balance of Payments -A Financial Center View. Law and Contemporary Problems, 34(1), pp. 33-46. 
Lopez, J. and A. Cruz (2000): Thirlwall's Law and beyond Latin American Experience. Journal of Post Keynesian Economics. Spring, 22(3), pp. 477-495.

Loría, E. Y G. Fuji (1997). The Balance of Payments Constraint to Mexico's Economic Growth 1950-1996. Canadian Journal of Development Studies, 18(1), pp. 119-137.

Loría, E. (2003). The Mexican Economy: Balance of Payments Constrained Growth Model the importance of the Exchange Rate, 1970-1999, Journal of Post Keynesian Economics, $25(4)$, pp. 659-663.

McKinnon, R. (1981). The Exchange Rate and Macroeconomic Policy: Changing Postwar Perceptions". Journal of Economic Literature, 19(3), pp. 531-537.

Md. Abdus Salam (1995). The Balance of Payment as a Monetary Phenomenon: An Econometric Study of India's Experience. The Indian Economic Journal, 42(3), pp. 76-82.

Moreno-Brid, J. C. (1999). Mexico's Economic Growth and the Balance of Payments Constraint: A Cointegration Analysis, International Review of Applied Economics, 13(2), pp. 149-159.

Moreno-Brid, J.C. (2003). Capital Flows, Interest Payments and the Balance of Payments Constrained Growth Model: A Theoretical and Empirical Analysis, Metroeconomica, Vol. 54, pp. 346-365.

Mundell, R. A. (1971). Monetary Theory: Inflation, Interest and Growth in the World Economy. Pacific Palisades: Goodyear.

Obstfeld, M., and K. Rogoff (1995). Exchange Rate Dynamics Redux. Journal of Political Economy, 103(3), pp. 624-660.

Obstfeld, M., and K. Rogoff (1999). New Directions for Stochastic Open Economy Models. Journal of International Economics, 50(1), pp. 117-153.

Ocegueda Hernández, J. M. (2003): El Sector Manufacturero y la Restricción Externa al Crecimiento Económico de México, Revista de Desarrollo, 34(132), pp. 77-110.

Polak, J. (1957). Monetary Analysis of Income Formation and Payments Problems. Staff Papers I.M.F, No. 6.

Prebisch, R. (1959). Commercial Policy in the Underdeveloped Countries. The American Economic Review, 49(2), pp. 251-273.

Schumpeter, J. A. (1934). The Theory of Economic Development: An inquiry into profits, capital, credit, interest and the Business Cycle. Cambridge,Mass: Harvard University Press. 10 Edición 2004. USA.

Spinelli, F. (1983). Currency Substitution, Flexible Exchange Rates, and the Case for International Monetary Cooperation: IMF Staff Papers, 30(4), pp. 755-783.

Taylor, L. (1994). "Gap Models". Journal of Development Economics, 45(1), pp. 17-34.

Thirlwall, A. P. (1979). The Balance of Payments Constraint as an Explanation of International Growth Rate Differences. Banca Nazionale del Lavoro. Quarterly Review,32(128), pp. 45-53.

Velasco, R. (2006). ?'Hay restricción externa del crecimiento en Colombia de 1925 a 2000?, Cuadernos de Economía, 25(44), pp. 99-118.

Velastegui, L. (2007). Crecimiento Económico en el Ecuador y Restricciones en la Balanza de Pagos: Una Aplicación a la Ley de Thirlwall. 1970-2004. Serie de análisis económico, 4. Ecuador.

Wilford, D. S, and W. T. Wilford (1978). On the Monetary Approach to the Balance of Payments: The Small, Open Economy. The Journal of Finance. 33(1), pp. 319-323. 